\title{
Wire-over-wire technique
}

Usually guidewires are used to lead catheters or other medical devices through the human body. For the first time, we present a technique of advancing a guidewire over another guidewire without the use of a catheter.

We developed a new guidewire (Patent \# DDE102015204065A1E102015204065-

A1; MTW Endoskopie Manufaktur, Wesel, Germany). The guidewire tip can be angulated in two planes to form a three-dimensional helix. This tip is twisted around a first guidewire and then this novel second guidewire can be advanced alongside the first guidewire ( $\triangleright$ Video 1 ). The soft guidewire tip is only $30 \mathrm{~mm}$ in length and shorter than the 50 -mm soft tips used in most other guidewires. This helps the guidewire not to bend passively when being advanced into a stenosis. With the help of a torquing device, the tip of the guidewire can be rotated to steer the direction of further cannulation.

The maneuver can be performed outside or even inside the bile ducts. In $>$ Video 1 we demonstrate the application of the new technique during papillary cannula-

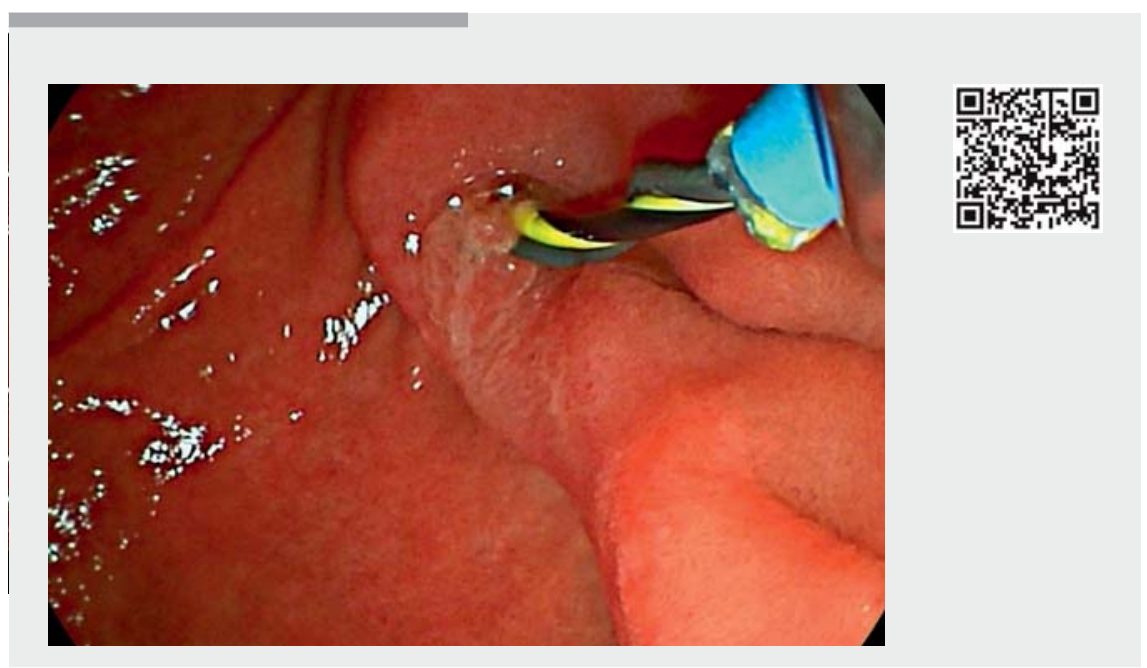

Video 1 Wire-over-wire technique. The tip of this novel guidewire is twisted around another previously placed guidewire. Thus the second guidewire can follow exactly the route of the first guidewire. The maneuver can be performed outside or even inside the bile ducts Two cases of papillary cannulation are shown and one case of targeted biliary branch cannulation. tion in two cases and in targeted biliary branch cannulation in one example.

We see a potential use in cannulation of narrowed proximal bile ducts in combination with dilated distal bile ducts, as frequently seen in anastomotic or hilar strictures. Possibly this technique might facilitate pseudocyst cannulation, with a second wire for stent implantation after a first wire has been introduced through an endoscopic ultrasound (EUS) needle. The wire-over-wire technique can lead the second wire always in the direction of the first wire even if the first wire is bent, and it does not depend on the cannulation angle, unlike cannulation with a catheter. In addition, the wire can facilitate deep intrahepatic biliary cannulation even in complex stenosis because of its three-dimensional capability.

In summary, the use of this special wire has the potential to enable new endoscopic methods and will be investigated accordingly.

Endoscopy_UCTN_Code_TTT_1AR_2AK

\section{Competing interests}

J.W. is the inventor of the wire. He receives payments for license of selly the wire from the university of Magdeburg.

The authors

Jochen Weigt, Wilfried Obst, Ali Canbay

Department of Gastroenterology,

Hepatology, and Infectious Diseases, Otto von Guericke University, Magdeburg, Germany

\section{Corresponding author}

\section{Jochen Weigt, MD}

Department of Gastroenterology, Hepatology, and Infectious Diseases, Otto-v.-Guericke University Magdeburg, Leipziger Str. 44, 39120 Magdeburg, Germany

Fax: +49-391-6713105

Jochen.weigt@med.ovgu.de

\section{Bibliography}

DOI https://doi.org/10.1055/a-0866-9028

Published online: 25.3.2019

Endoscopy 2019; 51: E137

(c) Georg Thieme Verlag KG

Stuttgart · New York

ISSN 0013-726X

\section{ENDOSCOPY E-VIDEOS}

https://eref.thieme.de/e-videos

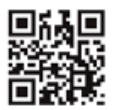

Endoscopy E-Videos is a free access online section, reporting on interesting cases and new techniques in gastroenterological endoscopy. All papers include a high quality video and all contributions are freely accessible online.

This section has its own submission website at https://mc.manuscriptcentral.com/e-videos 